\title{
Photos of Two Small Resident Owls
} by Doug Gilroy, Brora, Saskatchewan

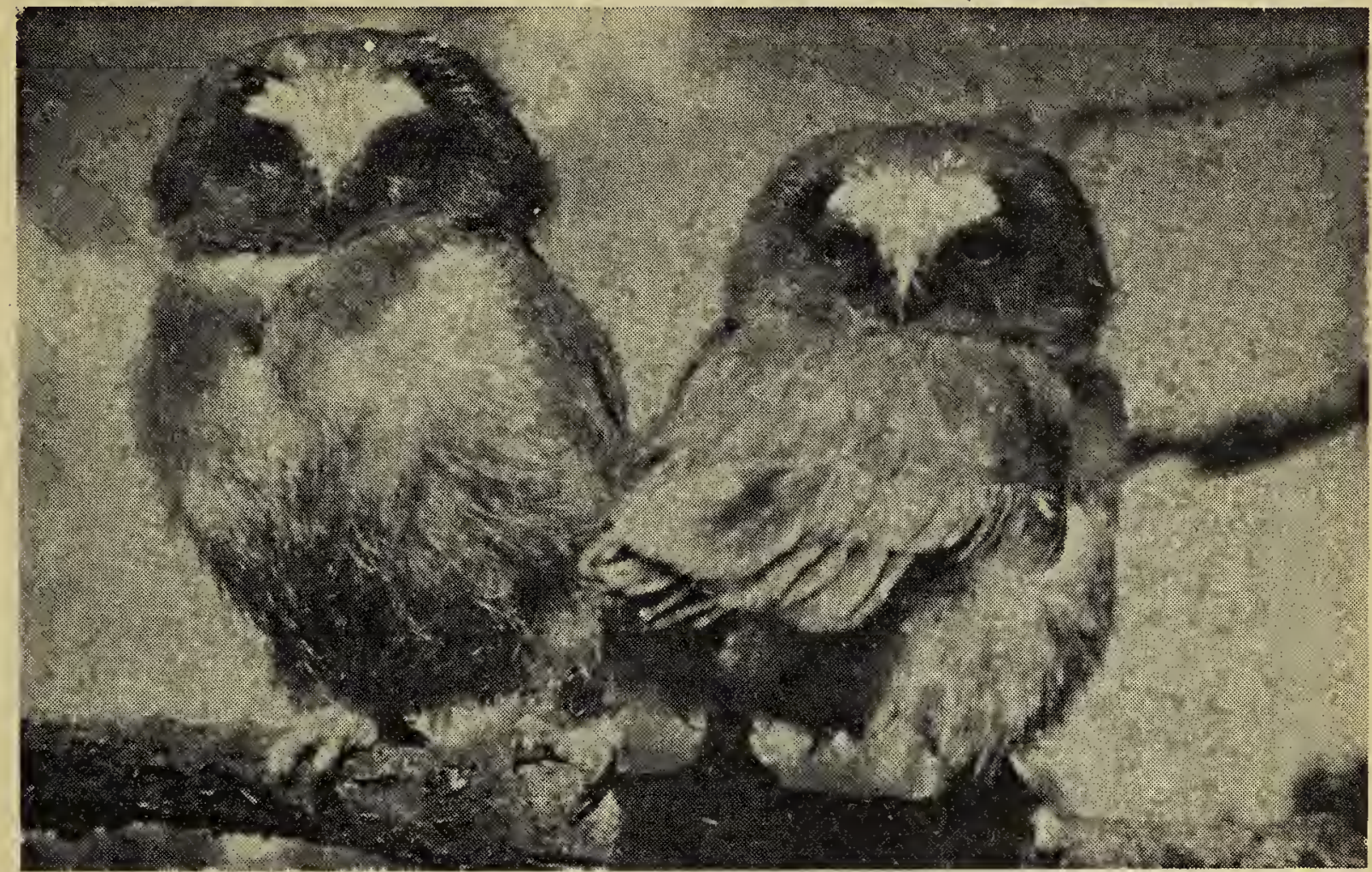

These two young Saw-whet Owls have emerged from their tree-trunk nest. Two days after this photograph was taken, the owls were gone. Note the distinct light patch. on the young owls' foreheads which is quite different from the spotted markings of the adult bird.

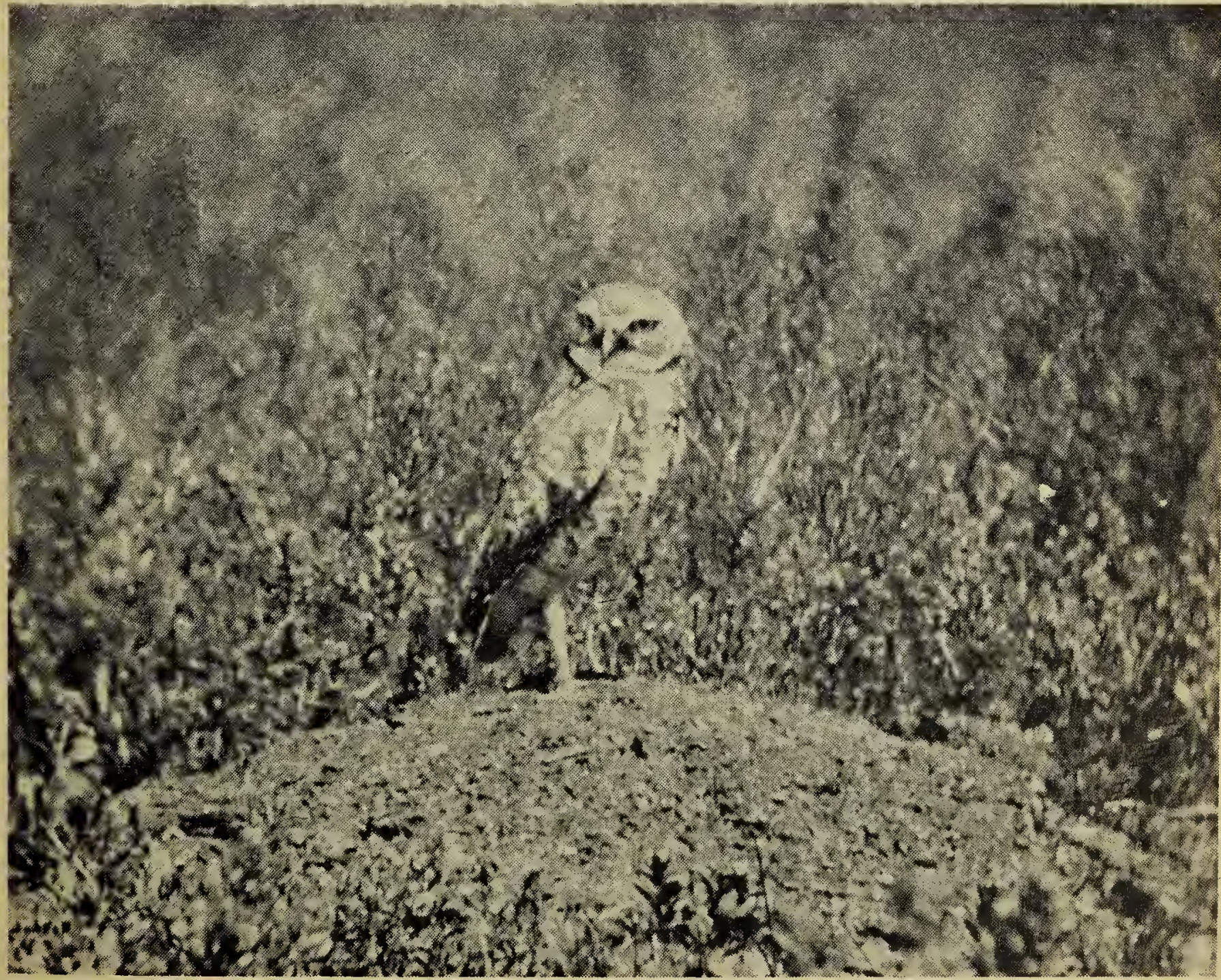

Unlike the Saw-whet which nests in trees, this small awl-the Burrowing Owl-is a ground nester. Here the adult bird watches from the mound above its burrow. 